
\title{
25 Research Soure \\ Excess Risk of Mortality Due to Heatwaves in Dezful city, Southwest of Iran
}

\section{Hamidreza Aghababaeian}

Tehran University of Medical Sciences

Abbas Ostadtaghizadeh ( $\nabla$ ostadtaghizadeh@gmail.com )

Tehran University of Medical Sciences

\section{Ali Ardalan}

Tehran University of Medical Sciences

\author{
Ali Asgary \\ York University \\ Mehry Akbary \\ Kharazmi University \\ Mir Saeed Yekaninejad \\ Tehran University of Medical Sciences \\ Rahim Sharafkhani \\ Khoy University of Medical Sciences \\ Carolyn Stephens \\ UCL Bartlett Development Planning Unit
}

\section{Research Article}

Keywords: Climate change, Death, Extreme weather events, Heatwave, Mortality

Posted Date: June 25th, 2021

DOl: https://doi.org/10.21203/rs.3.rs-646456/v1

License: (c) (1) This work is licensed under a Creative Commons Attribution 4.0 International License.

Read Full License 


\section{Abstract}

Background: Recent studies show that heatwaves pose risks to human health. Iran is exposed to heatwaves, but the evidence for the health impact of heatwaves is scarce. We aimed to evaluate the impact of heatwaves on daily deaths from non-accidental, cardiovascular, and respiratory in the city of Dezful in Iran from 2013 to 2019.

Method: We collected daily ambient temperature and mortality and defined two types of heatwaves by combining daily temperature ${ }^{3} 90^{\text {th }}$ in each month of the study period or since 30 years with duration ${ }^{3} 2$ and 3 days. We used a distributed lag non-linear model to investigate the association between each type of heatwave definition and deaths from non-accidental, cardiovascular, and respiratory with lags up to 13 days.

Results: Heat waves of both definitions were associated with a higher risk of non-accidental mortality. The association between heat waves and mortality appeared acutely and lasted for 3 and 4 days. The main effect and added effect are more pronounced among male and older adults than their counterparts. We found no evidence of an association of cardiovascular and respiratory deaths with heat waves.

Conclusion: Dezful is a city with a hot climate. However, the results showed that heatwaves could have detrimental effects on health, even in populations accustomed to the extreme heat. Therefore, early warning systems which monitor heat waves should provide the necessary warnings to all exposed groups, especially the elderly and the male groups.

\section{Background}

One of the growing natural hazards around the world is increasing extreme heat known as 'heatwaves' often linked to climate change [1] . Various studies show that heatwaves have severe negative effects on human health [2-5]. Due to the increasing global temperature [5-8] and the subsequent increasing frequency and severity of the weather events [7,9], heatwaves became important health concerns worldwide [5-7]. Prior studies provide evidence that heat waves are associated with increased risk of deaths, hospitalizations, and emergency visits [10-19]. Heat waves are projected to increase in frequency, length and intensity due to the continued climate change $[20,21]$.

Understanding the relationship between heatwaves and health is critical for better planning, mitigation strategies, preparedness and timely response [22]. This is complex: the association between temperature and health outcome depends on climatic zone and latitude and it is therefore necessary to study the health impacts of heatwaves in different latitudes [23] and specific climatic conditions. Although the effects of heatwaves, especially health effects, have been explored in several settings internationally, but most heatwave studies have been conducted in temperate or cold regions [23].

There are limited studies on the effects of heatwaves on health in the Middle East in general and in Iran in particular [24]. In recent years, studies on the effect of heatwaves on health had been conducted by 
Ahmadzadeh et al. in 2014, Sharafkhani et al. in 2020 and Aboubakri et al. in 2019 in three cold regions in Iran (Tehran, Urmia and Kerman cities, respectively) $[16,17,25,26]$. These regions have a completely different climate from Khuzestan province and the city of Dezful, located in the southwest of Iran. There are few studies in developing countries that have examined the effects of heat waves and their impact on public health in areas with hot climates or high-average temperatures [14, 27]. For example, there were studies done in India, which has a hot climate, but the average, minimum, and maximum base temperatures of the studied cities differ than that of Dezful $[14,27]$. Although many studies have been carried out across the world on the effects of heatwaves on health, the harmful health consequences of this type of natural hazard in areas with hot climates have not been fully identified [24]. Dezful is a city in a region with hot and humid climate, where the temperature reaches above 50 degrees Celsius in the summer, one of the hottest cities in the world. Consequently, it is necessary to study and measure the effects of this natural disaster on the health of people in this city. This study aims to assess the effect of heatwaves on mortality as the most important health criterion.

\section{Materials And Methods}

We use an ecological time series model to investigate the relationship between heat waves and daily nonaccidental, respiratory, and cardiovascular deaths in the city of Dezful from 2013 to 2019.

\section{Location and climate of Dezful:}

Dezful is a city with a hot and humid climate [28-30], located in the north of Khuzestan province in Southwest of Iran (Figure 1) [31]. It is located $142 \mathrm{~m}$ above the sea level [28, 29]. According to the 2016 census, Dezful had a population of 444,000 . It has warm summers (sometimes Sultry) and Mediterranean winters. The average temperature in Dezful is $3^{\circ} \mathrm{C}$ in winter and $49^{\circ} \mathrm{C}$ in summer and the average annual rainfall in the city is about $400 \mathrm{~mm}$ [28-30]. Annual Weather Averages Summery are provided in the Supplementary Material (Additional file 1: Appendix 1).

\section{Mortality data}

We obtained daily mortality data between 2013 and 2019 from the Deputy of Health at the Dezful University of Medical Sciences. Cause-specific mortality was coded according to $10^{\text {th }}$ revision of International Classification of Diseases (ICD-10): non-accidental (ICD-10: A00-R99), cardiovascular (ICD10: I00-199), and respiratory diseases (ICD-10: J00-J99). Daily deaths were then aggregated by age ( $<15$, $15-64,65-74$, and 375 years) and sex (male versus female).

\section{Meteorological data}

We obtained daily maximum temperature, minimum temperature, maximum relative humidity, and minimum humidity from the Islamic Republic of Iran Meteorological Organization. We calculated daily mean temperature by taking the average of maximum and minimum temperature, and daily mean relative humidity by taking the average of maximum and minimum relative humidity. We also obtained daily 
$\mathrm{PM}_{2.5}$ and $\mathrm{PM}_{10}$ between 2013 and 2019 from the Khuzestan Department of Environment. Locations are provided in the Supplementary Material (Additional file 1: Appendix 2).

\section{Definitions of heatwaves}

Sincere there is no global consensus on the definition of a 'heatwave', particularly in settings with average high temperatures. We considered two definitions based on prior studies [32]. For the first definition, we defined heat wave as daily maximum temperature ${ }^{3} 90^{\text {th }}$ percentile of maximum temperature in each month of the current study period with duration ${ }^{3} 2$ days [33-35]. For the second definition, we defined heat wave as daily maximum temperature ${ }^{3} 90^{\text {th }}$ percentile of maximum temperature since last 30 years ago [1983-2012] with duration ${ }^{3} 3$ days [17]. Details are provided in the Supplementary Material (Additional file 2: Appendix 1).

\section{Design}

We assessed both the main and added effect of heat wave on mortality $[15,36]$. The main effect of heat wave was used to investigate the effects of heat, and the added effect of heat wave was to examine the effects caused by heat persistence $[15,36]$. In this study, all the heatwaves in Dezful city occurred during the warm months from 21 March to 21 October (which is equal to the beginning of Farvardin month till the end of Mehr in the Persian calendar). We calculated the main effects as the risk of mortality at the median temperature among the heat wave days relative to the risk of death at the $65^{\text {th }}$ percentile of annual temperature distribution, which temperature percentile was the percentile at the lowest risk of mortality (Additional file 2: Appendix 2) $[15,16]$. We calculated the added effect as the risk of deaths during heat wave days relative to non-heat wave days. Details are provided in the Supplementary Material (Additional file 2: Appendix 3).

\section{Statistical analysis}

Given that the distribution of daily deaths follows the Poisson distribution, we estimated the association between heat wave and deaths using a quasi-Poisson regression combined with a distributed lag nonlinear model. The distributed lag nonlinear model allows us to model both the nonlinear and delayed effects of heat wave. We modeled the lag function using a natural cubic B-spline with $x x$ knots placed at equal intervals on the logarithmic scale of the lags up to 13 days.[15, 16, 36].

$\log E\left[Y_{t}\right]=a+c b\left(T_{1}, 2,3\right)+c b\left(T_{2}, 2,3\right)+n s\left(P M_{10}, d f=3\right)+n s\left(P M_{2.5}, d f=1\right)+n s(R H, d f=2)+n s$ (Season, $d f=3)+n s(T i m e, d f=7)+D O W+$ Holidays

Where $Y_{t}$ is the number of deaths on day $t, T_{1}$ refers to the main effect, that is a 2 dimensional natural spline with 2 degree of freedom (df) for temperature $(T)$ and $3 \mathrm{df}$ for lagged temperatures, with maximum lag as $13 . T_{2}$ refers to added effect, which is a binary variable assuming value 1 during the heat wave, with maximum lag as 13 . Effect of potential confounders controlled by natural spline function. Relative humidity $(\mathrm{RH})$ with $2 \mathrm{df}, \mathrm{PM}_{10}$ with $3 \mathrm{df}$ and $\mathrm{PM}_{2.5}$ with $1 \mathrm{df}$ [ns with $1 \mathrm{df}$ is a linear term]. Season means 
the variation during the warm season, that is adjusted by a natural spline with $3 \mathrm{df}$. The effect of time trend is adjusted by a natural spline with $7 \mathrm{df}$ per year. The effects of days of week (DOW) and holidays are adjusted by including categorical variables in the models. We conducted all analyses in R software (version 3.5.1) with the DLNM package to model the nonlinear and delayed effects of heat wave. Details are provided in the Supplementary Material (Additional file 2: Appendix 4).

\section{Sensitivity analysis}

In the two DLNM matrices constructed, the $d f$ for the variable and lags was selected based on the lowest Akaike Information Criterion (AIC) value. In both matrices, the degrees of lag freedom and degrees of variable freedom were tested between 2 and 5 . We used the lowest Quasi-Akaike information criterion value to guide the selection of the degrees of freedom for the lags and variables.

\section{Subgroup analysis}

To examine whether the effects of heat wave are varied by personal characteristics, we did subgroup analysis by age group $\left(<15,15-64,65-74\right.$, and ${ }^{3} 75$ years) and sex (male versus female).

\section{Results}

\section{Descriptive results}

Table 1 shows the meteorological, Heat Waves and mortality characteristics of Dezful city and the study population, and Heat Waves during the warm season from 2013 to 2019. The mean number of total nonaccidental daily mortality in Dezful during the study period was $8.33 \pm 3$. The daily temperature and humidity during the same period in Dezful were $24.6^{\circ} \mathrm{C} \pm 9.3^{\circ} \mathrm{C}$ and $51.2 \% \pm 21.2 \%$, respectively. Other Mortality, Meteorological, and Heatwaves characteristics are provided in the Table 1.

\section{The model results}

Table 2, Figure 2 and Figure 3 show the Cumulative excess risk in Dezful for non-accidental (NAD), cardiovascular and respiratory deaths (Additional file 3: Appendix 1 and 2). As these table and figures shows, Heat Waves were not related to cardiovascular and respiratory mortality, but in the main effects, the $\mathrm{HW}_{1}$ heat waves significantly increased the risk of $\mathrm{NAD}$ in $\operatorname{lag}_{0-2}$; and in addition, regarding $\mathrm{HW}_{2}$, heat waves significantly increased the risk of NAD in $\operatorname{lag}_{0}, \operatorname{lag}_{0-2}$ and $\operatorname{lag}_{0-6}$.

Also, in the added effects of the $\mathrm{HW}_{1}$, the risk of non-accidental death increased significantly in $\operatorname{lag}_{0}$ and $\operatorname{lag}_{0-2}$, In addition, regarding $\mathrm{HW}_{2}$, heat waves significantly increased the risk of non-accidental death in $\operatorname{lag}_{0}, \operatorname{lag}_{0-2}$ and $\operatorname{lag}_{0-6}$.

Figure 4 and Figure 5 also shows the Cumulative excess risk of non-accidental death for the city of Dezful based on age and sex. As shown in this Figures, in main and added effects, heat waves significantly increased the risk of non-accidental death in people over 75 years and the male group. 
In this regard, in the main effect and added effects, $\mathrm{HW}_{1}$ increases the risk of non-accidental death in the male group (Main effects: $\operatorname{lag}_{0-2}(13.56 ; 0.4827 .27)$, and Added effects: $\operatorname{lag}_{0-2}(13.56 ; 0.4827 .27)$ ). In addition, the main effects of the $\mathrm{HW}_{2}$ significantly increased the risk of death for people over 75 years old and was determined in the $\operatorname{lag}_{0}(15.84 ; 0.4733 .57)$ and $\operatorname{lag}_{0-2}(32.53 ;(0.6768 .17)$. For the male group, there was a significant increase in the risk for $\operatorname{lag}_{0}(17.83 ; 4.5832 .75)$ and $\operatorname{lag}_{0-2}(39.61 ; 12.1569 .77)$. In addition, in the added effects of the $\mathrm{HW}_{2}$, the risk of death for people over 75 years old in $\operatorname{lag}_{0}(9.47 ; 0.14$ 19.67) and lag $0-2(19.91 ; 0.4140 .81)$ increased significantly. This noteworthy increase was also evident in the male group in the same conditions in the $\operatorname{lag}_{0}(11.25 ; 3.2719 .84), \operatorname{lag}_{0-2}(25.23 ; 8.5942 .86)$ and $\operatorname{lag}_{0-6}(30.53 ; 1.35$ 61.12) (Additional file 3: Appendix).

\section{Discussion}

In this study, we found that heatwaves are associated with a higher risk of non-accidental mortality in Dezful city, which has much higher base temperature than most previous studies about heatwaves and health.

Our results are similar to the findings of some other studies with the same temperature and cold regions $[24,37,38]$. In this regard, Linares (2015) stated that, in Spain increasing each Celsius degree of daily maximum temperature from the threshold of $37^{\circ} \mathrm{C}$ could increase the risk of mortality by 10.3 $\%$ [39]. Also, similar results were found in studies conducted in Brazil [40] and India [14, 27]. In these studies, which examined the effect of heatwaves on the mortality of four cities with high average temperatures, Nouri Sarma (2019) and Azhar (2014) found that the risk of death on days with heatwaves has increased significantly $[14,27]$. This shows that high temperatures, even in communities that are adapted to the extreme heat, can have adverse effects on the health of the exposed people. The heatrelated deaths may occur in exposed humans due to increased blood viscosity, and known clinical syndromes such as heatstroke, dehydration, and cardiovascular diseases [14, 27, 41, 42]. Moreover, the results show that heatwaves significantly increase the risk of non-accidental death in the male group and those over the age of 75. The results of most similar studies support the findings of this study on the stronger effect of heatwaves on the risk of death of the elderly [15, 43-45]. This might be due to the reduced capacity of elderly to regulate temperature and taking medication that can intervene with the natural sweating process. $[46,47]$.

In terms of the greater effects of heatwaves on the increased risk of death in the male group, in some studies the male group had a higher risk of death than females [19, 37]; however, in other studies, females were more likely at risk of death from heatwaves than the male group $[15,45]$. These differences may be related to the lifestyle, economic context, and social and cultural characteristics of the people of each community [15]. Importantly, any change in any of the above cases can change the vulnerability of men and women to heatwaves. 
Although elevated ambient temperature is associated with airway hyper-responsiveness, fluid and electrolyte imbalance, increased heart rate, and plasma cholesterol, the cardiovascular and respiratory effects of exposure to heat waves are inconsistent in several studies [48]. The results of this study show that heatwaves can increase the risk of cardiovascular death in all lags. However, for respiratory death, this increase occurred only slightly in the initial lag and in other lags, the risk of respiratory deaths was reduced, although the consequences of these deaths were insignificant. In this regard, Ahmadzadeh (2014) in Iran [17] and Woo (2011) in Australia [44] had also discussed the risk of cardiovascular death in heatwaves and had noted that the risk of death is more due to respiratory diseases. So it is possible to say that the risk of respiratory death in areas with colder temperatures is higher than in areas with hot temperatures [17]. Some studies report a higher risk of respiratory death than cardiovascular death [49]. These differences in results are due to differences in the definition of heatwaves, heat intensity, and time and duration of heatwaves in each study $[50,51]$. Notably, due to the insignificant numbers of respiratory deaths, it was not possible to track the impact of heatwaves on daily mortality of this nature. Therefore, it is suggested that future studies investigate the relationship between heatwaves and specific deaths in more detail and for larger populations.

From these results, we also note the importance of choosing the correct definitions of heatwaves in each region. According to the type of definitions and their results, it is estimated that each community is required to determine a precise definition of heatwaves in its region. In this study, the two definitions of heatwaves did not produce the same results for mortality. Further studies need to examine various definitions of heatwaves and their relationship with key health indicators. Finally, in this study, the results show that the effects of heatwaves on the risk of death in the main effect are more remarkable than the added effect. In this regard Gasperini and Armstrong (2011) concluded in a study in some American cities, the risk of death due to heatwaves in the main effects is much higher than the added effects [36]. To justify the results of the current study, it can be stated that the higher risk of death in the baseline effects versus the added effects may be due to the announcements of the high temperature early warning systems in Khuzestan province, followed by more compliance to the necessary measures by citizens to prevent health effects. Lin (2013) also stated that people may be physiologically and psychologically adaptable to a higher temperature for more than a few days which may justify the results of this study [52]. The results of the current study can be more strongly generalized by studying the impact of heatwaves by including more respiratory deaths.

\section{Limitations Of The Study}

In this study, we only considered the outdoor ambient temperature, and we did not know the exact location of the deaths and the temperature there, because there may have been people at home who died there as well. Also, in Dezful, the amount of ozone is not fully measured, Therefore, we could not evaluate the possible effects of ozone in this study. Finally, we only included the data from the city of Dezful and its surrounding suburbs in our study, because the life pattern, temperature and humidity of other cities in Khuzestan province may not be consistent with the city of Dezful and its suburbs. 


\section{Conclusion}

As confirmed in this and other similar studies, people living in areas with extremely high temperature do experience risks to their health from heatwaves, despite the common misconception that people are not vulnerable to heatwaves in the tropics. The specific climate of each region, the degree of exposure, repetition of heatwaves, and body adaptation are important to understand in each setting, and it may be important for each setting to develop its own specific heatwave definition. In the context of global warming, especially in the Middle East and Iran, these findings can be of great help to policymakers in planning and subsequent policy-making to establish early warning systems. It is recommended that more studies need to be conducted on the effect of other definitions of heatwaves on public health in different regions. It is also recommended that other studies on specific causes of death be carried out in more detail, and over a longer period.

\section{Abbreviations}

ICD: International Classification of Diseases; T: Temperature; DT: Daily Temperature; DRH: Daily relative humidity; RH: Relative humidity; IRIMO: Islamic Republic of Iran Meteorological Organization; ER: Excess Risk; RR: Relative Risk; CER: Cumulative Excess Risk; DLNM: Distributed Lag Non-linear Model; AIC: Akaike Information Criterion

\section{Declarations}

\section{Acknowledgments}

Many thanks to Institute for School of public health and Environmental Research (IER) of TUMS, for funded and supported current study (Grant No: 98-03-46-43717).

\section{Authors' contributions}

"HA, AOT and MA designed the study; HA collected the data; HA, RSH, and MSY analyzed and interpreted the data. HA, AOT, A Ardalan, RSH, CS and A Asgary prepared the manuscript. All authors contributed to the drafting and final review of the manuscript. The author (s) read and approved the final manuscript."

\section{Funding}

This study is a part of PhD dissertation and was funded and supported by School of public health and Center for air pollution research (CAPR), institute for environmental research (IER), Tehran University of Medical Sciences, Tehran, Iran, Grant No: 98-03-46-43717.

\section{Availability of data and materials}

The datasets used and/or analysed during the current study available from the corresponding author on reasonable request. 


\section{Ethics approval and consent to participate}

Current study was approved by the Ethics Committee of Tehran University of Medical Sciences (TUMS) Ethics Code: IR.TUMS.SPH.REC.1399.004, and also all methods were performed in accordance with the relevant guidelines and regulations. This study does not require informed consent directly from the patient since only unnamed archived data has been used. Therefore, the consent has been waived by the ethics committee. However, written permission was obtained from the competent authorities to use this data.

\section{Consent for publication}

Not applicable.

\section{Competing interests}

The authors declare that they have no conflicts of interest.

\section{Author details}

${ }^{1-}$ Department of Health in Emergencies and Disasters, School of Public Health, Tehran University of Medical Sciences, Tehran, Iran. ${ }^{2-}$ Center for air pollution research (CAPR), institute for environmental research (IER), Tehran University of Medical Sciences, Tehran, Iran. ${ }^{3-D e p a r t m e n t ~ o f ~ N u r s i n g ~ a n d ~}$ Emergency, Dezful University of Medical Sciences, Dezful, Iran. ${ }^{4}$-Disaster and Emergency Management, School of Administrative Studies, York University, Toronto, Canada. ${ }^{5-D e p a r t m e n t ~ o f ~ C l i m a t o l o g y, ~ F a c u l t y ~}$ of Geographical Sciences, Kharazmi University, Tehran, Iran. ${ }^{6}$-Department of Epidemiology and Biostatistics, School of Public Health, Tehran University of Medical Sciences, Tehran, Iran. ${ }^{7}$ School of Public Health, Khoy University of Medical Sciences, Khoy, Iran. ${ }^{8-}$ Honorary Full Professor, UCL Bartlett Development Planning Unit, London. UK.

\section{References}

1. IPCC data for eg Intergovernmental Panel on Climate Change (IPCC) (2021) [https://www.ipcc.ch ]

2. Cheng J, Xu Z, Bambrick H, Su H, Tong S, Hu W: Heatwave and elderly mortality: An evaluation of death burden and health costs considering short-term mortality displacement. Environment international 2018, 115:334-342.

3. Coates L, Haynes K, O'brien J, McAneney J, De Oliveira FD: Exploring 167 years of vulnerability: an examination of extreme heat events in Australia 1844-2010. Environmental Science \& Policy 2014, 42:33-44. 
4. Forzieri G, Cescatti A, e Silva FB, Feyen L: Increasing risk over time of weather-related hazards to the European population: a data-driven prognostic study. The Lancet Planetary Health 2017, 1(5):e200e208.

5. Mora C, Dousset B, Caldwell IR, Powell FE, Geronimo RC, Bielecki CR, Counsell CW, Dietrich BS, Johnston ET, Louis LV: Global risk of deadly heat. Nature climate change 2017, 7(7):501-506.

6. Royé D, Codesido R, Tobías A, Taracido M: Heat wave intensity and daily mortality in four of the largest cities of Spain. Environmental Research 2020, 182:109027.

7. Pachauri RK, Allen MR, Barros VR, Broome J, Cramer W, Christ R, Church JA, Clarke L, Dahe Q, Dasgupta P: Climate change 2014: synthesis report. Contribution of Working Groups I, II and III to the fifth assessment report of the Intergovernmental Panel on Climate Change: Ipcc; 2014.

8. Sheridan SC, Allen MJ: Changes in the frequency and intensity of extreme temperature events and human health concerns. Current Climate Change Reports 2015, 1(3):155-162.

9. Schleussner C-F, Pfleiderer P, Fischer EM: In the observational record half a degree matters. Nature Climate Change 2017, 7(7):460.

10. Robine J-M, Cheung SLK, Le Roy S, Van Oyen H, Griffiths C, Michel J-P, Herrmann FR: Death toll exceeded 70,000 in Europe during the summer of 2003. Comptes rendus biologies 2008, 331(2):171-178.

11. Filleul L, Cassadou S, Médina S, Fabres P, Lefranc A, Eilstein D, Le Tertre A, Pascal L, Chardon B, Blanchard M: The relation between temperature, ozone, and mortality in nine French cities during the heat wave of 2003. Environmental Health Perspectives 2006, 114(9):1344-1347.

12. Knowlton K, Rotkin-Ellman M, King G, Margolis HG, Smith D, Solomon G, Trent R, English P: The 2006 California heat wave: impacts on hospitalizations and emergency department visits. Environmental health perspectives 2009, 117(1):61-67.

13. Dole R, Hoerling M, Perlwitz J, Eischeid J, Pegion P, Zhang T, Quan XW, Xu T, Murray D: Was there a basis for anticipating the 2010 Russian heat wave? Geophysical Research Letters 2011, 38(6).

14. Azhar GS, Mavalankar D, Nori-Sarma A, Rajiva A, Dutta P, Jaiswal A, Sheffield P, Knowlton K, Hess $\mathrm{JJ}$ : Heat-related mortality in India: Excess all-cause mortality associated with the 2010 Ahmedabad heat wave. PLoS One 2014, 9(3):e91831.

15. Zeng W, Lao X, Rutherford S, Xu Y, Xu X, Lin H, Liu T, Luo Y, Xiao J, Hu M: The effect of heat waves on mortality and effect modifiers in four communities of Guangdong Province, China. Science of the Total Environment 2014, 482:214-221.

16. Sharafkhani R, Khanjani N, Bakhtiari B, Jahani Y, Entezarmahdi R: The effect of cold and heat waves on mortality in Urmia a cold region in the North West of Iran. Journal of Thermal Biology 2020, 
94:102745.

17. Ahmadnezhad E HN, Ardalan A, Mahmoudi M, Yonesian M, Naddafi K, Mesdaghinia AR Excess mortality during heat waves, Tehran Iran: an ecological time-series study. 2013.

18. Basu R: High ambient temperature and mortality: a review of epidemiologic studies from 2001 to 2008. Environmental health 2009, 8(1):40.

19. Bell ML, O'neill MS, Ranjit N, Borja-Aburto VH, Cifuentes LA, Gouveia NC: Vulnerability to heatrelated mortality in Latin America: a case-crossover study in Sao Paulo, Brazil, Santiago, Chile and Mexico City, Mexico. International journal of epidemiology 2008, 37(4):796-804.

20. Stocker TF, Qin D, Plattner G-K, Tignor MM, Allen SK, Boschung J, Nauels A, Xia Y, Bex V, Midgley PM: Climate Change 2013: The physical science basis. contribution of working group I to the fifth assessment report of IPCC the intergovernmental panel on climate change. In.: Cambridge University Press; 2014.

21. Field CB: Climate change 2014-Impacts, adaptation and vulnerability: Regional aspects: Cambridge University Press; 2014.

22. Meehl GA, Tebaldi C: More intense, more frequent, and longer lasting heat waves in the 21st century. Science 2004, 305(5686):994-997.

23. McMichael AJ, Wilkinson P, Kovats RS, Pattenden S, Hajat S, Armstrong B, Vajanapoom N, Niciu $\mathrm{EM}$, Mahomed $\mathrm{H}$, Kingkeow $\mathrm{C}$ : International study of temperature, heat and urban mortality: the 'ISOTHURM'project. International journal of epidemiology 2008, 37(5):1121-1131.

24. Campbell S, Remenyi TA, White CJ, Johnston FH: Heatwave and health impact research: A global review. Health \& place 2018, 53:210-218.

25. Aboubakri O, Khanjani N, Jahani Y, Bakhtiari B: Attributable risk of mortality associated with heat and heat waves: a time-series study in Kerman, Iran during 2005-2017. Journal of thermal biology 2019, 82:76-82.

26. Aboubakri O, Khanjani N, Jahani Y, Bakhtiari B: The impact of heat waves on mortality and years of life lost in a dry region of Iran (Kerman) during 2005-2017. International journal of biometeorology 2019, 63(9):1139-1149.

27. Nori-Sarma A, Anderson GB, Rajiva A, ShahAzhar G, Gupta P, Pednekar MS, Son J-Y, Peng RD, Bell ML: The impact of heat waves on mortality in Northwest India. Environmental research 2019, 176:108546.

28. Geographical and climatic features of Khuzestan province [http://khzmet.ir/image/climakh.pdf] 
29. Dezful General information [http://www.dezful.ir/fa-

IR/DouranPortal/4652/page/\%D8\%AA\%D8\%A7\%D8\%B1\%DB\%8C\%D8\%AE\%DA\%86\%D9\%87]

\section{DEZFUL WEATHER AVERAGES}

SUMMARY [https://www.weatherbase.com/weather/weather.php3?s=59704\&cityname=DezfulKhuzestan-IranWEATHER ]

31. Aghababaeian H, Dastoorpoor M, Ghasemi A, Kiarsi M, Khanjani N, Ahvazi LA: Cardiovascular and respiratory emergency dispatch due to short-term exposure to ambient PM10 in Dezful, Iran. Journal of Cardiovascular and Thoracic Research 2019, 11(4):264.

32. Xu Z, FitzGerald G, Guo Y, Jalaludin B, Tong S: Impact of heatwave on mortality under different heatwave definitions: a systematic review and meta-analysis. Environment international 2016, 89:193203.

33. Tong S, Wang XY, Barnett AG: Assessment of heat-related health impacts in Brisbane, Australia: comparison of different heatwave definitions. PloS one 2010, 5(8):e12155.

34. Beniston M, Diaz HF: The $\mathbf{2 0 0 3}$ heat wave as an example of summers in a greenhouse climate? Observations and climate model simulations for Basel, Switzerland. Global and planetary change 2004, 44(1-4):73-81.

35. Tong S, FitzGerald G, Wang X-Y, Aitken P, Tippett V, Chen D, Wang X, Guo Y: Exploration of the health risk-based definition for heatwave: A multi-city study. Environmental research 2015, 142:696-702.

36. Gasparrini A, Armstrong B: The impact of heat waves on mortality. Epidemiology (Cambridge, Mass) 2011, 22(1):68.

37. Hajat S, Armstrong BG, Gouveia N, Wilkinson P: Mortality displacement of heat-related deaths: a comparison of Delhi, Sao Paulo, and London. Epidemiology 2005:613-620.

38. Hajat S, Armstrong B, Baccini M, Biggeri A, Bisanti L, Russo A, Paldy A, Menne B, Kosatsky T: Impact of high temperatures on mortality: is there an added heat wave effect? Epidemiology 2006:632638.

39. Linares C, Diaz J, Tobías A, Carmona R, Mirón I: Impact of heat and cold waves on circulatorycause and respiratory-cause mortality in Spain: 1975-2008. Stochastic environmental research and risk assessment 2015, 29(8):2037-2046.

40. Diniz FR, Gonçalves FLT, Sheridan S: Heat Wave and Elderly Mortality: Historical Analysis and Future Projection for Metropolitan Region of São Paulo, Brazil. Atmosphere 2020, 11(9):933.

41. Rooney C, McMichael AJ, Kovats RS, Coleman MP: Excess mortality in England and Wales, and in Greater London, during the 1995 heatwave. Journal of Epidemiology \& Community Health 1998, 
52(8):482-486.

42. Keatinge WR, Coleshaw SR, Easton JC, Cotter F, Mattock MB, Chelliah R: Increased platelet and red cell counts, blood viscosity, and plasma cholesterol levels during heat stress, and mortality from coronary and cerebral thrombosis. The American journal of medicine 1986, 81(5):795-800.

43. Lin Y-K, Ho T-J, Wang Y-C: Mortality risk associated with temperature and prolonged temperature extremes in elderly populations in Taiwan. Environmental research 2011, 111(8):1156-1163.

44. Yu W, Mengersen K, Hu W, Guo Y, Pan X, Tong S: Assessing the relationship between global warming and mortality: lag effects of temperature fluctuations by age and mortality categories. Environmental pollution 2011, 159(7):1789-1793.

45. Son J-Y, Lee J-T, Anderson GB, Bell ML: The impact of heat waves on mortality in seven major cities in Korea. Environmental health perspectives 2012, 120(4):566-571.

46. Basagaña X, Sartini C, Barrera-Gómez J, Dadvand P, Cunillera J, Ostro B, Sunyer J, MedinaRamón M: Heat waves and cause-specific mortality at all ages. Epidemiology 2011:765-772.

47. Schifano P, Cappai G, De Sario M, Michelozzi P, Marino C, Bargagli AM, Perucci CA: Susceptibility to heat wave-related mortality: a follow-up study of a cohort of elderly in Rome. Environmental Health 2009, 8(1):50.

48. Cheng J, Xu Z, Bambrick H, Prescott V, Wang N, Zhang Y, Su H, Tong S, Hu W: Cardiorespiratory effects of heatwaves: A systematic review and meta-analysis of global epidemiological evidence. Environmental research 2019, 177:108610.

49. D'Ippoliti D, Michelozzi P, Marino C, De'Donato F, Menne B, Katsouyanni K, Kirchmayer U, Analitis A, Medina-Ramón M, Paldy A: The impact of heat waves on mortality in 9 European cities: results from the EuroHEAT project. Environmental Health 2010, 9(1):37.

50. Medina-Ramon M, Schwartz J: Temperature, temperature extremes, and mortality: a study of acclimatisation and effect modification in $\mathbf{5 0}$ US cities. Occupational and environmental medicine 2007, 64(12):827-833.

51. Vandentorren S, Bretin P, Zeghnoun A, Mandereau-Bruno L, Croisier A, Cochet C, Ribéron J, Siberan I, Declercq B, Ledrans M: August 2003 heat wave in France: risk factors for death of elderly people living at home. The European Journal of Public Health 2006, 16(6):583-591.

52. Lin H, Zhang Y, Xu Y, Xu X, Liu T, Luo Y, Xiao J, Wu W, Ma W: Temperature changes between neighboring days and mortality in summer. a distributed lag non-linear time series analysis. PloS one 2013, 8(6):e66403. 


\section{Tables}

Table 1 Mortality, Meteorological, and Heatwaves characteristics of Dezful city (2013-2019) 


\begin{tabular}{|c|c|}
\hline Variable & Value \\
\hline \multicolumn{2}{|l|}{ Daily death number: Mean (SD) } \\
\hline Non-accidental & $8.3(3)$ \\
\hline Respiratory & $0.6(0.6)$ \\
\hline Cardiovascular & $3.5(1.9)$ \\
\hline \multicolumn{2}{|l|}{ Age: Mean (SD) } \\
\hline$<15$ & $1.1(1.1)$ \\
\hline $15-64$ & $2.8(1.7)$ \\
\hline $65-75$ & $1.1(1)$ \\
\hline$\geq 75$ & $3.1(1.8)$ \\
\hline \multicolumn{2}{|l|}{ Sex: Mean (SD) } \\
\hline Male & $4.8(2.2)$ \\
\hline Female & $3.4(1.9)$ \\
\hline \multicolumn{2}{|c|}{ Daily temperature $\left({ }^{\circ} \mathrm{C}\right):$ Mean (SD) } \\
\hline Daily temperature (Mean (SD)) & $24.6^{\circ} \mathrm{C}\left(9.3^{\circ} \mathrm{C}\right)$ \\
\hline Minimum temperature & $17.1^{\circ} \mathrm{C}\left(7.8^{\circ} \mathrm{C}\right)$ \\
\hline Maximum temperature & $33^{\circ} \mathrm{C} \quad\left(10.7^{\circ} \mathrm{C}\right)$ \\
\hline \multicolumn{2}{|c|}{ Daily Relative Humidity (\%): Mean (SD) } \\
\hline DRH (\%)[Mean (SD)] & $51.2 \% \quad(21.2 \%)$ \\
\hline \multicolumn{2}{|l|}{ Heat waves characteristic } \\
\hline \multicolumn{2}{|c|}{ Number per year [mean (Min, Max)] } \\
\hline Heat wave definition ${ }_{1} a$ & $6(2,7)$ \\
\hline Heat wave definition ${ }_{2} b$ & $6.6(2,8)$ \\
\hline \multicolumn{2}{|c|}{ Average heat wave intensity $\left({ }^{\circ} \mathrm{C}\right)$ [mean (Min, Max)] } \\
\hline $\mathrm{HW}_{1}$ & $44.7^{\circ} \mathrm{C}\left(35.5^{\circ} \mathrm{C}, 51.2^{\circ} \mathrm{C}\right)$ \\
\hline HW2 & $47.9^{\circ} \mathrm{C}\left(47^{\circ} \mathrm{C}, 51.2^{\circ} \mathrm{C}\right)$ \\
\hline \multicolumn{2}{|c|}{ Average heat wave duration [mean (Min, Max)] } \\
\hline $\mathrm{HW}_{1}$ & $2.6(2,6)$ \\
\hline & $4.1(3,13)$ \\
\hline
\end{tabular}




\begin{tabular}{|lr|}
$\mathrm{HW}_{2}$ & \\
Start date of heat wave/year (Earliest, Latest) \\
$\mathrm{HW}_{1}$ & 28 Mar to 10 Oct \\
$\mathrm{HW}_{2}$ & 11 Apr to $30 \mathrm{Sep}$ \\
\hline
\end{tabular}

${ }^{\text {aHeat }}$ wave definition ${ }_{1}$ was defined as daily maximum temperature $\geq 90$ th percentile of maximum temperature in each month of the current study period with duration $\geq 2$ days

${ }^{b}$ Heat wave definition ${ }_{2}$ was defined as daily maximum temperature $\geq 90$ th percentile of maximum temperature since last 30 years ago [1983-2012] with duration $\geq 3$ days

Table 2 the cumulative excess risk of non-accidental, respiratory and cardiovascular deaths due to heat waves. 


\begin{tabular}{|c|c|c|c|c|c|}
\hline \multirow[t]{2}{*}{ Death } & \multirow{2}{*}{$\begin{array}{l}\text { Lag } \\
\text { day }\end{array}$} & \multicolumn{2}{|c|}{ Heat wave definition 1} & \multicolumn{2}{|c|}{ Heat wave definition 2} \\
\hline & & Main effect & Added effect & Main effect & Added effect \\
\hline \multirow[t]{4}{*}{ Non-accidental } & 0 & $\begin{array}{l}4.60(-0.12 \\
9.56)\end{array}$ & $\begin{array}{l}1.79(0.02 \\
3.59) * * *\end{array}$ & $\begin{array}{l}12.48(2.81 \\
23.05) * * \star\end{array}$ & $\begin{array}{l}7.76(1.88 \\
13.99) * \star \star\end{array}$ \\
\hline & $0-2$ & $\begin{array}{l}10.43(0.63 \\
20.59) * * *\end{array}$ & $\begin{array}{l}4.11(0.44 \\
7.83) * \star *\end{array}$ & $\begin{array}{c}29.20(8.99 \\
50.88) * \star \star\end{array}$ & $\begin{array}{l}18.35(5.99 \\
31.25) * \star \star\end{array}$ \\
\hline & $0-6$ & $\begin{array}{l}12.78(-4.47 \\
30.55)\end{array}$ & $\begin{array}{l}5.18(-1.31 \\
11.76)\end{array}$ & $\begin{array}{l}38.86(3.35 \\
76.44) * \star \star\end{array}$ & $\begin{array}{c}24.87(2.96 \\
47.56) \star \star \star\end{array}$ \\
\hline & $0-13$ & $\begin{array}{l}8.17(-23.01 \\
40.18)\end{array}$ & $\begin{array}{l}3.10(-8.75 \\
15.08)\end{array}$ & $\begin{array}{l}21.96(-40.19 \\
87.41)\end{array}$ & $\begin{array}{l}14.09(-24.78 \\
54.24)\end{array}$ \\
\hline \multirow[t]{4}{*}{ Cardiovascular } & 0 & $\begin{array}{l}2.56(-3.04 \\
8.50)\end{array}$ & $\begin{array}{l}0.89(-1.22 \\
3.05)\end{array}$ & $\begin{array}{l}8.95(-2.50 \\
21.77)\end{array}$ & $\begin{array}{l}5.30(-1.76 \\
12.87)\end{array}$ \\
\hline & $0-2$ & $\begin{array}{l}5.64(-6.03 \\
17.83)\end{array}$ & $\begin{array}{l}2.02(-5.32 \\
10.43)\end{array}$ & $\begin{array}{l}19.42(-4.64 \\
45.68)\end{array}$ & $\begin{array}{l}11.70(-3.18 \\
27.41)\end{array}$ \\
\hline & $0-6$ & $\begin{array}{l}6.46(-14.16 \\
27.82)\end{array}$ & $\begin{array}{l}2.50(-5.32 \\
10.43)\end{array}$ & $\begin{array}{l}21.27(-21.16 \\
66.77)\end{array}$ & $\begin{array}{l}13.35(-13.10 \\
40.98)\end{array}$ \\
\hline & $0-13$ & $\begin{array}{l}5.88(-31.65 \\
44.63)\end{array}$ & $\begin{array}{l}1.98(-12.33 \\
16.46)\end{array}$ & $\begin{array}{l}13.82(-61.75 \\
94.35)\end{array}$ & $\begin{array}{l}8.25(-39.19 \\
57.61)\end{array}$ \\
\hline \multirow[t]{4}{*}{ Respiratory } & 0 & $\begin{array}{l}0.01(-18.20 \\
22.23)\end{array}$ & $\begin{array}{l}-0.90(-8.19 \\
6.97)\end{array}$ & $\begin{array}{l}1.29(-30.56 \\
47.77)\end{array}$ & $\begin{array}{l}1.10(-22.09 \\
25.54)\end{array}$ \\
\hline & $0-2$ & $\begin{array}{l}-3.48(-41.83 \\
41.34)\end{array}$ & $\begin{array}{l}-3.30(-18.59 \\
12.92)\end{array}$ & $\begin{array}{l}-6.65(-74.65 \\
84.77)\end{array}$ & $\begin{array}{l}-8.34(-53.18 \\
45.67)\end{array}$ \\
\hline & $0-6$ & $\begin{array}{l}-16.22(-84.71 \\
61.31)\end{array}$ & $\begin{array}{l}-8.48(-36.75 \\
20.10)\end{array}$ & $\begin{array}{l}-41.40(-163.9 \\
114.1)\end{array}$ & $\begin{array}{l}-30.91(-112.1 \\
63.4)\end{array}$ \\
\hline & $0-13$ & $\begin{array}{l}-15.59(-142.01 \\
125.8)\end{array}$ & $\begin{array}{l}-7.96(-57.8 \\
44.1)\end{array}$ & $\begin{array}{l}-48.74(-278.1 \\
236.2)\end{array}$ & $\begin{array}{l}-34.33(-184.7 \\
137.8)\end{array}$ \\
\hline
\end{tabular}

Labels: Bold typeface with ${ }^{\star * *: ~ i n d i c a t e s ~ s t a t i s t i c a l ~ s i g n i f i c a n c e ~ a t ~} p<0.05$.

${ }^{\text {a Heat wave definition }}{ }_{1}$ was defined as daily maximum temperature $\geq 90$ th percentile of maximum temperature in each month of the current study period with duration $\geq 2$ days

${ }^{b}$ Heat wave definition ${ }_{2}$ was defined as daily maximum temperature $\geq 90$ th percentile of maximum temperature since last 30 years ago [1983-2012] with duration $\geq 3$ days

\section{Figures}




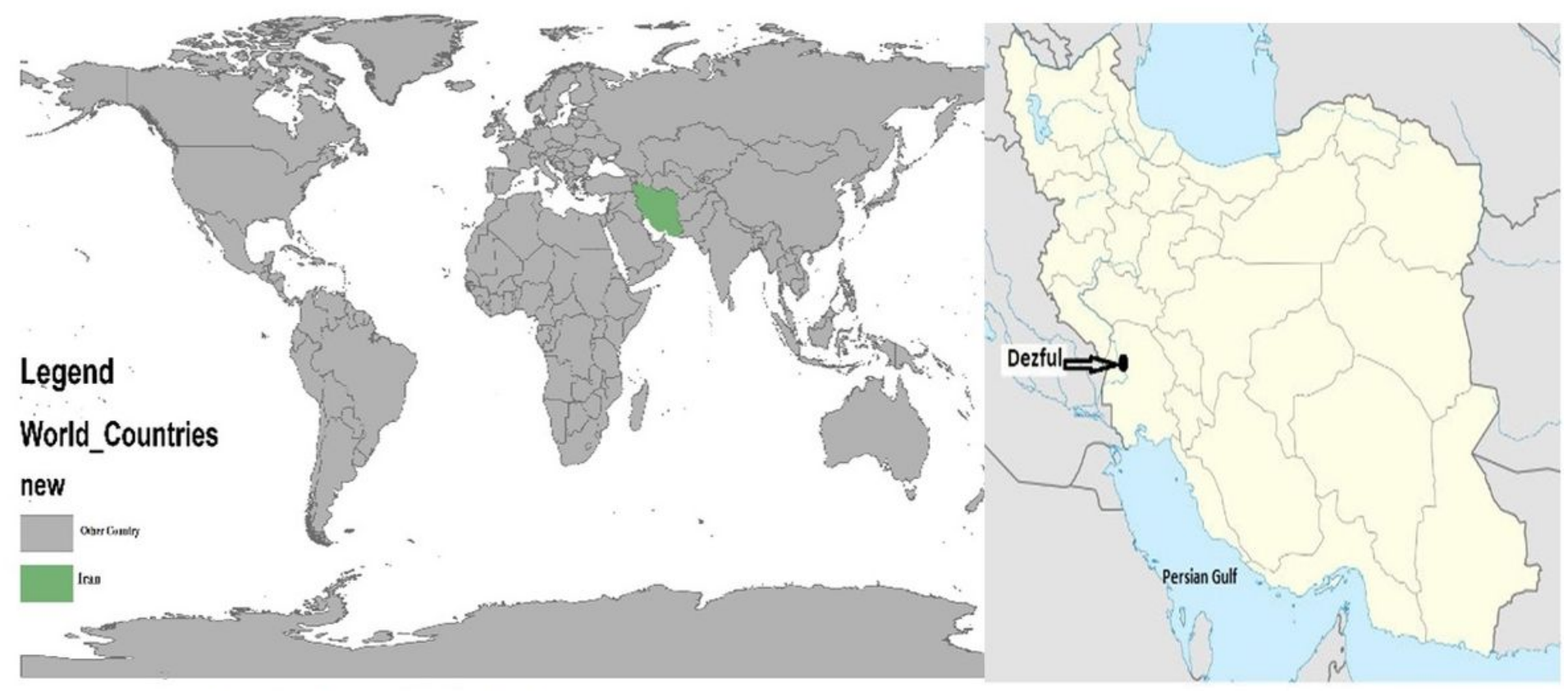

Created by: Hamidreza Aghababaeian- Arc Map 10.8

\section{Figure 1}

Map of world (left), map of Iran (right) with Dezful indicated Note: The designations employed and the presentation of the material on this map do not imply the expression of any opinion whatsoever on the part of Research Square concerning the legal status of any country, territory, city or area or of its authorities, or concerning the delimitation of its frontiers or boundaries. This map has been provided by the authors. 


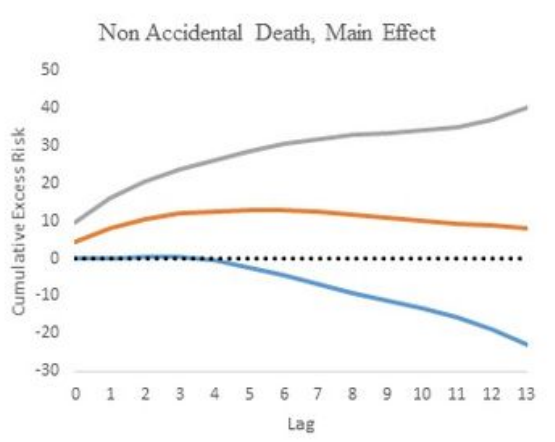

Non Accidental Death, Added Effect

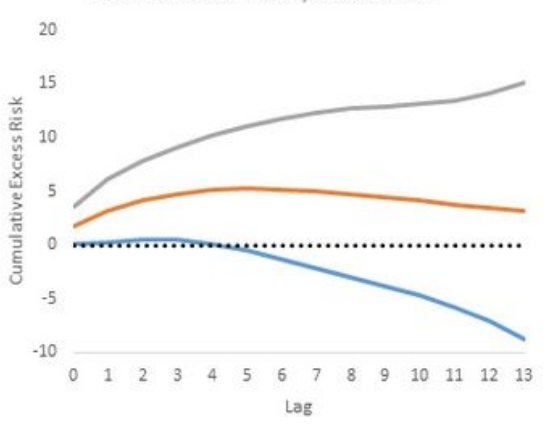

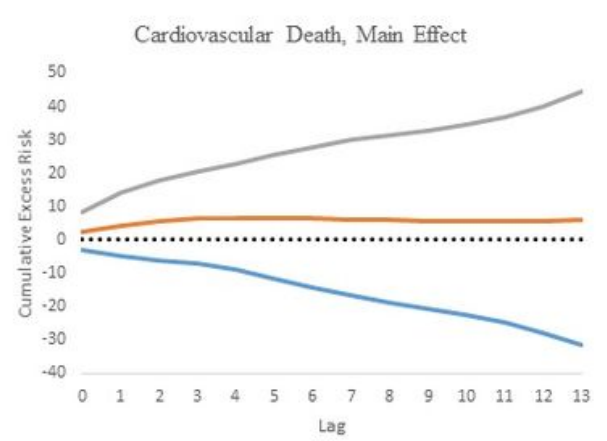
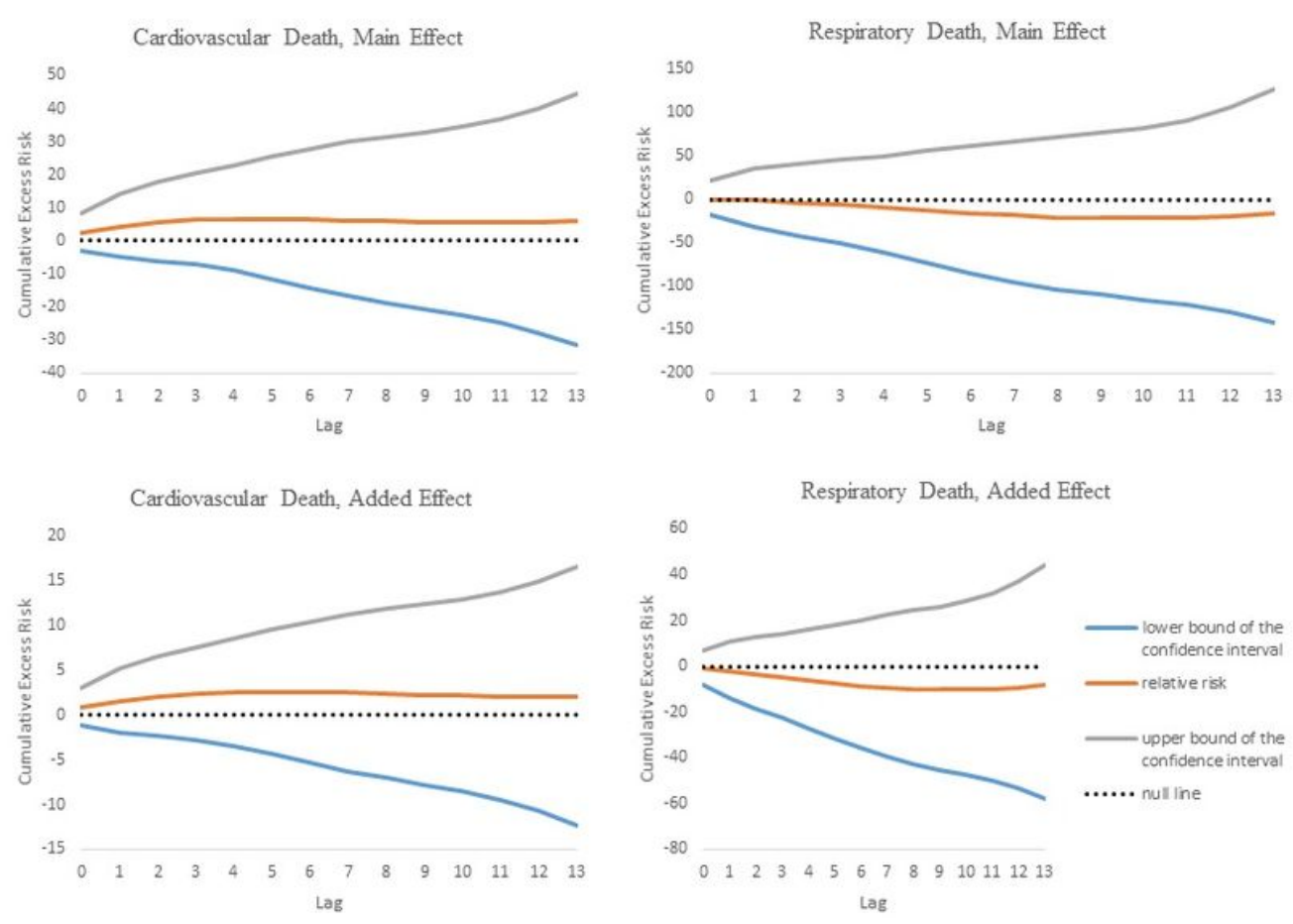

\section{Figure 2}

\section{Cumulative excess risk of Non Accidental Death, Cardiovascular Death and Respiratory Death by HW1}
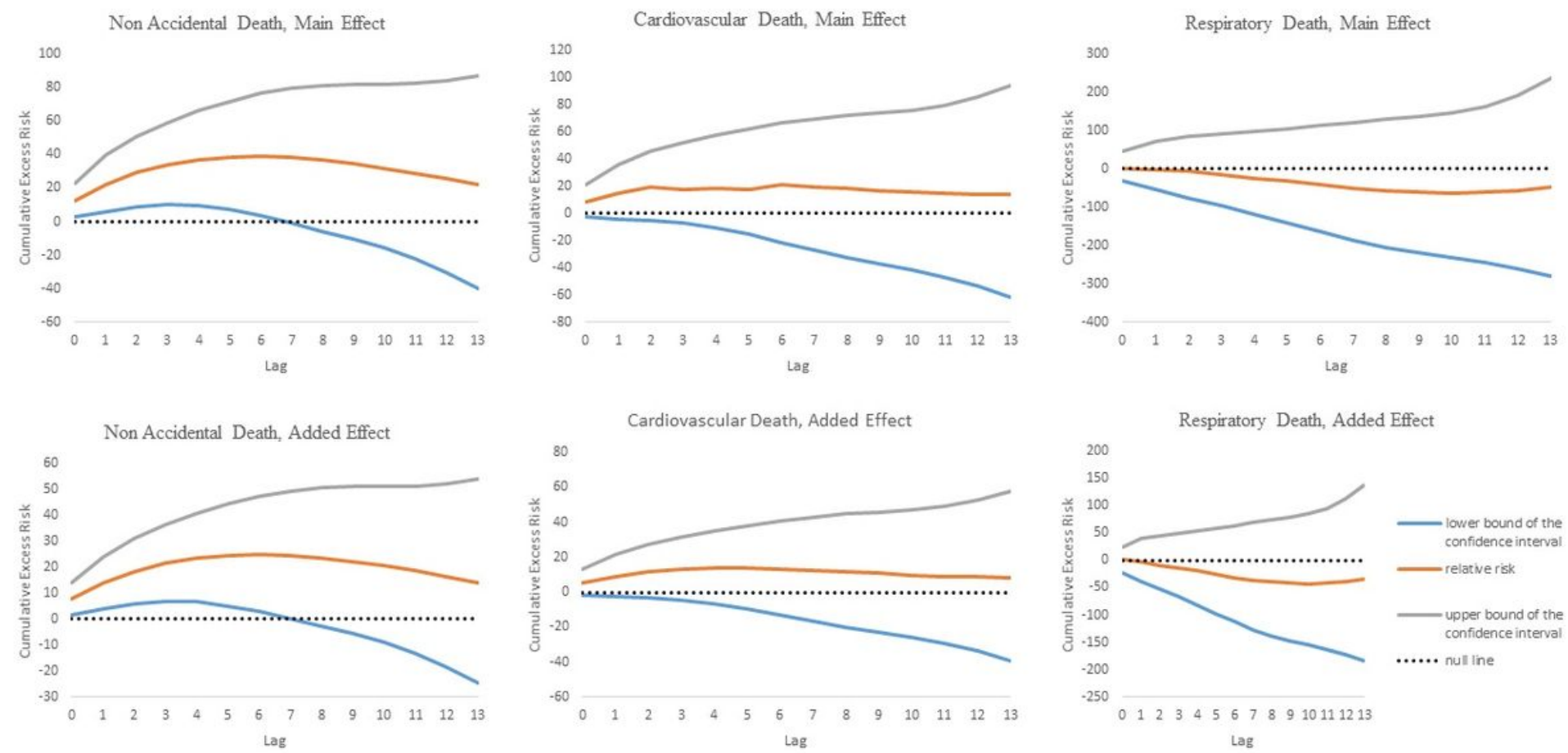


\section{Figure 3}

\section{Cumulative excess risk of Non Accidental Death, Cardiovascular Death and Respiratory Death by HW2}
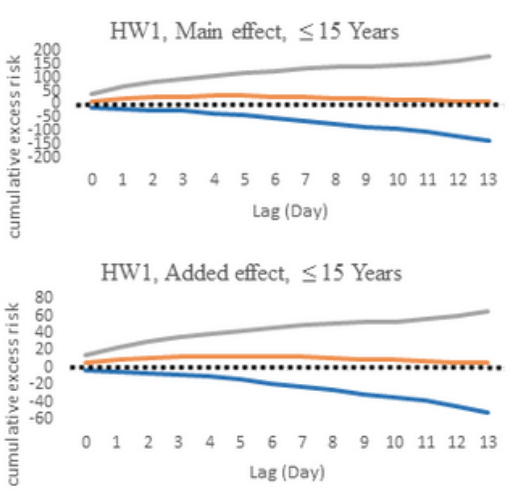

HW1, Main effect, $\geq 75$ Years

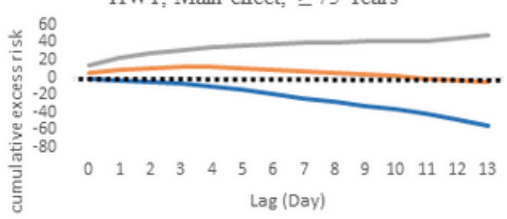

HW1, Added effect, $\geq 75$ Years

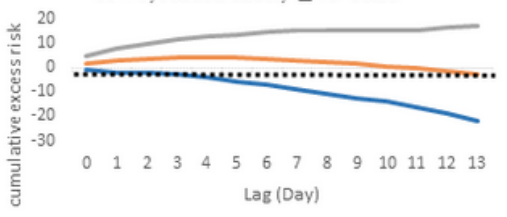

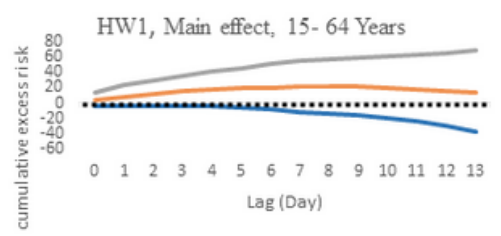

HW1, Added effect, 15-64 Years

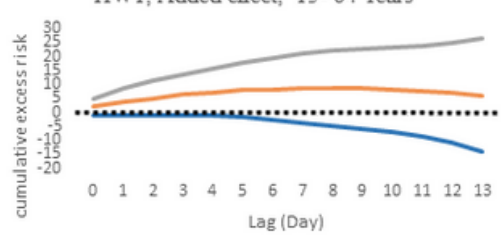

HW1, Main effect, Male
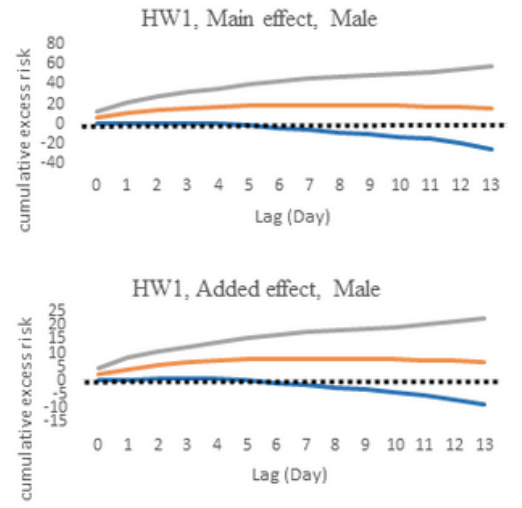

HW1, Main effect, 65- 74 Years

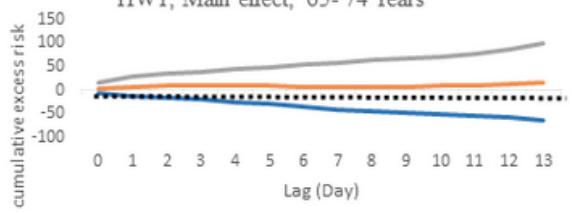

HW1, Added effect, 65-74 Years

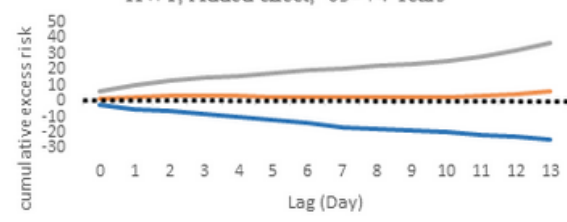

HW1, Main effect, Female

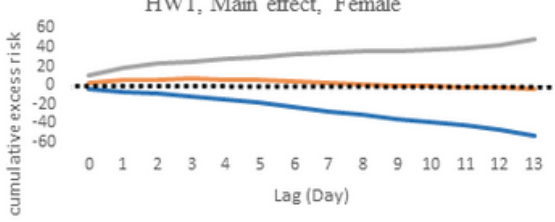

HW1, Added effect, Female

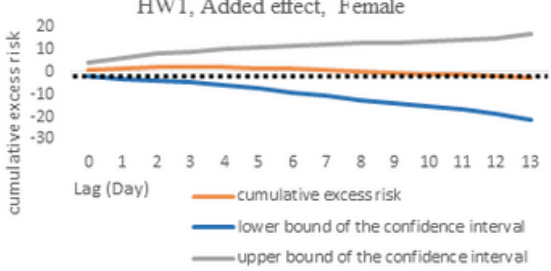

\section{Figure 4}

Cumulative Excess Risk of Non Accidental Death in Dezful based on age and sex by HW1 

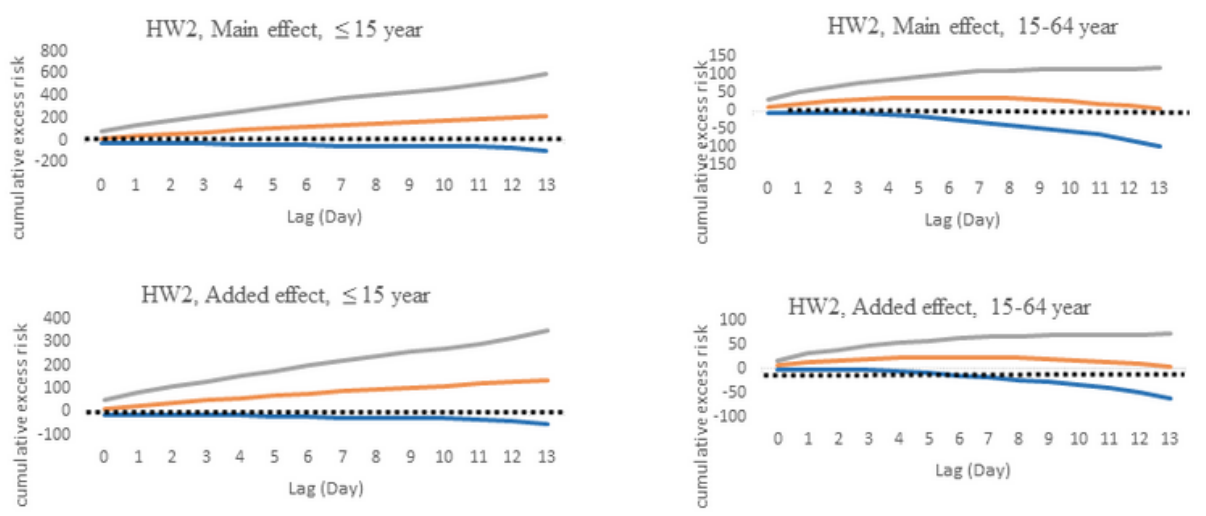

HW2, Main effect, $\geq 75$ year

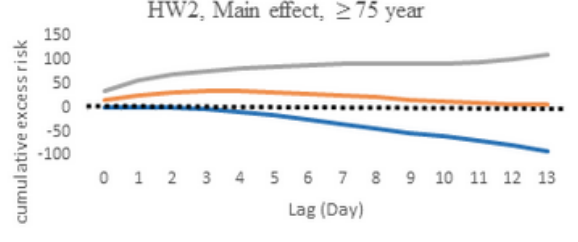

HW2, Added effect, $\geq 75$ year

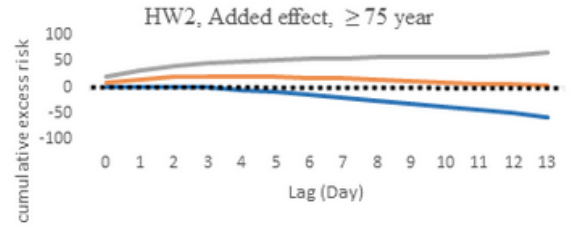

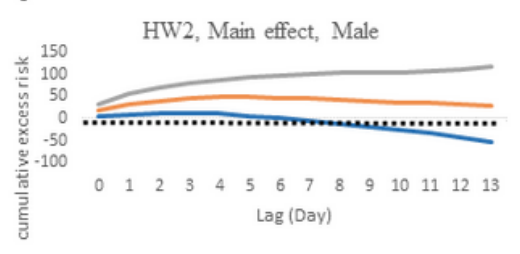

HW2, Added effect, Male

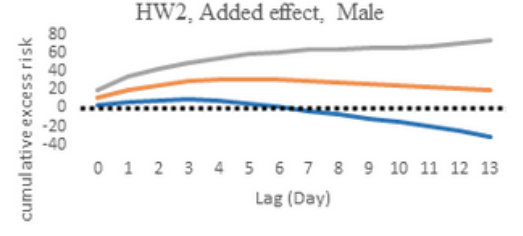

HW2, Main effect, 65-74 year

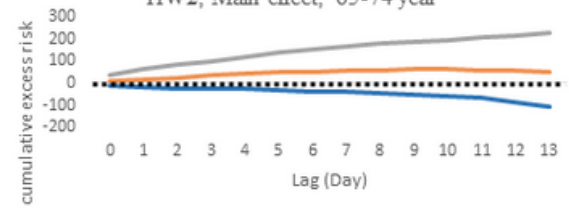

HW2, Added effect, 65-74 year

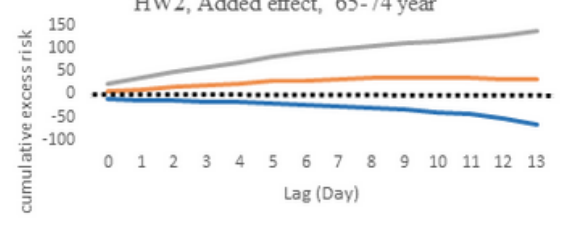

HW2, Main effect, Female

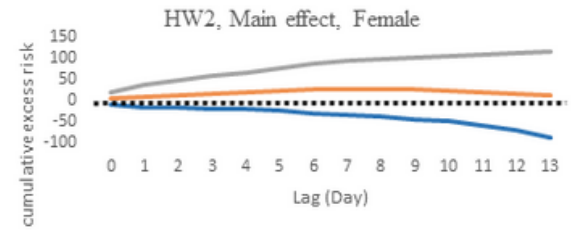

HW2, Added effect, Female

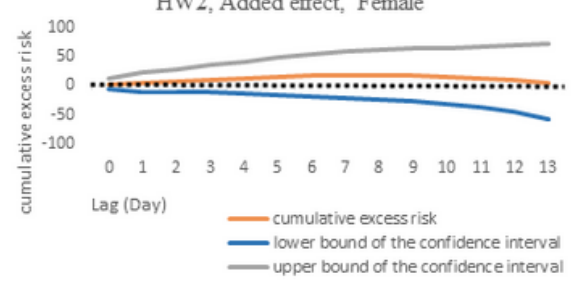

\section{Figure 5}

Cumulative Excess Risk of Non Accidental Death in Dezful based on age and sex by HW2

\section{Supplementary Files}

This is a list of supplementary files associated with this preprint. Click to download.

- Additionalfile1.docx

- Additionalfile2.docx

- Additionalfile3.docx 